\title{
Feeling Stereotyped and its Effects on Investment Decisions*
}

\author{
KYOUNGMI LEE ${ }^{* *}$ \\ Seoul National University \\ Seoul, Korea
}

\begin{abstract}
How do consumers respond in financial contexts when a negative stereotype about an ingroup is salient? I predicted and found that, in such circumstances, consumers consistently preferred safe investment options to riskier yet potentially better-pay-off ones, as compared to the situation in which a negative ingroup stereotype is not salient. The results of three experiments suggest that consumers tend to prefer stable securities (e.g., Treasury bonds or stocks with low betas) versus unstable securities (e.g., stocks with high betas) when a negative stereotype to their group is made salient.
\end{abstract}

Keywords: Stereotype Threat, Investment Decisions, Risk-taking tendency, Avoidance Motivation

\section{INTRODUCTION}

As many contexts as there are groups, consumers encounter the abundant contexts in which their groups are associated with negative traits or stereotypes. Not only because of the prevalence

* This research was supported by a Daelim Suam research grant (DAELIM SUAM 2011-02) from Daelim Suam Foundation and the Institute of Management Research at Seoul National University.

** Associate professor, SNU Business School, Seoul National University. 1 Gwanakro, Gwanak-gu, Seoul, 08826 Republic of Korea; Phone: +82-2-880-2540; Email: kyoungmi@snu.ac.kr 
of such circumstances in the daily lives of consumers, but also because of the myriad consequences for individuals' performance and behavior, the detrimental effects of being considered as a member of a negatively stereotyped group have been extensively documented in the literature (Lee, Kim, and Vohs 2011; Steele and Aronson 1995; Steele, Aronson, and Spencer 2007). Those effects have been known to emerge in the contexts tied to the activated stereotype. For example, stereotype threat effect was found when the stereotyped individuals engage in tasks regarding the stereotyped domain (e.g., women taking math exams or Afro-American taking SAT).

In this research, I sought to examine whether reminding of a negative ingroup stereotype can affect people's general direction of behavior - approach or avoidance, affecting consumer judgments in the domains that are important for their well-being yet not directly tied to the negative stereotype. Specifically, the current research investigates this question in the investment decision domain and tries to provide implications for consumers' healthy financial decision making. In three experiments, I tested whether consumers reminding of or self-generating a negative ingroup stereotype would consistently adopt a risk avoidance tendency by preferring safer options to risky yet potentially lucrative investment options.

\section{STEREOTYPE THREAT AND MOTIVATION}

Stereotype threat has been studied extensively, albeit hardly in the area of financial decision making. A sizeable literature has demonstrated that an effect of feeling stereotyped is to make avoidance tendency. For instances, compared to women who were exposed to neutral or counter-stereotypic television commercials, women who watched gender-stereotypic television commercials subsequently avoided leadership roles in favor of nonthreatening subordinate roles (Davies, Spencer, and Steele 2005). Also, when people think that they can be stereotyped, they try to avoid chances that can show incompetence relative to others (Brodish and Devine 2009). And when consumers think that they may be stereotyped in a consumption context, avoiding outgroup service provider becomes the critical factor for their judgments about the transaction (Lee et al. 2011). Similarly, women who had been reminded of the math- 
gender stereotype (i.e., women's supposed inferior math ability as compared to men's) adopted the avoidance goal of not wanting to perform badly on a math test rather than the approach goal of wanting to perform well (Brodish and Devine 2009). Other work has shown that situations in which people are stereotyped create a prevention focus, which increases their sensitivity to the potential for negative outcomes (Seibt and Forster 2004).

From these findings in the literature, one can draw the conclusion that when people think that they are subject to a negative stereotype, inhibition rather than approach tendency may be activated. That is, people may become more attentive to the risk or punishment rather than rewards and vigilant to losses and errors. In this research, I raised two questions in particular. First, previous research has well demonstrated that stereotyped individuals engage in inhibition tendency in the domain relevant to the stereotype. Then, can this inhibition tendency be easily transferred to subsequent judgment that is not directly relevant to the stereotype domain?

Second, the deleterious consequences of being negatively and chronically stereotyped have been extensively documented in the stereotype threat literature (Steele 1997). It is not surprising, therefore, to see that individuals who are a part of disadvantaged groups tend to engage in an inhibited judgment and behavior. Then, would this inhibition tendency occur even for majority (versus minority) - group members who are not the target of chronically prominent negative stereotype in a society?

To address these issues, I focus on financial decision making since risk preferences can impact decision making and also its longterm effect. I propose that when a negative stereotype about one's ingroup is salient, consumers will become aversive to financial risk. Specifically, I propose that, in such circumstances, consumers may consistently prefer safer options and perceive risk as bigger, as compared to the situation in which a negative ingroup stereotype is not salient. Thus, I hypothesized that when a negative ingroup stereotype is salient versus not, consumers will become averse to financial risks.

H: when a negative ingroup stereotype is salient versus not, consumers will become averse to financial risks. 
I took the chain of experiments approach used in literature on stereotype threat effect (Spencer, Steele, and Quinn 1999) and tested my prediction using three experiments. In experiment 1, I predicted that women's financial decision making would change when they are reminded of the math-gender stereotype. In experiment 2, I examined that individuals' (not just minority group members) financial decision making would change when stereotype is activated through self-generated thoughts. In experiment 3, I provided converging evidence regarding increased preference for safer options after being reminded of negative ingroup stereotypes. Together, the results suggest that when a negative ingroup stereotype is salient, consumers become sensitive to the risk in financial decision making.

\section{EXPERIMENT 1: CREATING A PORTFOLIO OF STOCKS AND BONDS}

Experiment 1 focused on women's judgments in the domain of financial decision making. I systematically reminded (or not) female consumers of the gender-STEM stereotype by having them read an article about women's lower math skills than men or not having them read any article. This allowed me to establish the basic hypothesis that when the negative stereotype was salient, consumers would become averse to a financial risk. This study used a between-subjects design.

\section{Method}

Participants and Procedures. Thirty-four female undergraduates in a large university of North America participated as a partial course requirement. Participants in the experimental condition read an article about women's lower math skills than men. Those in the control condition did not read any article. Participants were then presented an ostensibly separate study. In the study, they were told that they needed to allocate a given fund to bonds or stocks in their portfolios. The percentage of funds to be allocated to bonds (vs. stocks) in their portfolios was measured as the key dependent variable. Since bonds are generally considered safer financial products than stocks, higher percentages of bods indicated the investment styles striving for less risk in exchange of more potential 
for making money. After completing demographic questions, participants were debriefed.

\section{Results}

I predicted that women would become more averse to a financial risk when the negative stereotype was salient (versus not). As expected, I found that people were less likely to prefer stocks (i.e., a riskier investment option) when they were reminded of their negative ingroup stereotype, relative when they were not $(F(1,32)=4.94$, $p<.05)$. Specifically, the women who read the article suggesting the validity of the gender-math stereotype allocated significantly more funds to bonds over stocks (59.29\% vs. 40.71\%), compared with when no such stereotype was in operation (46.13\% vs. $53.84 \%$ ).

\section{Discussion}

Consistent with the prediction, Experiment 1 found that consumers' financial decision was made in a way of pursuing less risky options, when they were reminded of a negative stereotype associated with their group membership. Specifically, women allocated funds to have more bonds and less stocks in their portfolio, when they read an article suggesting the stereotype that women are supposedly less competent at math than men. However, when women did not read any article and thereby were not reminded of the math-gender stereotype, their allocation of the funds to bonds versus stocks were not different. This finding indicates that consumers become more risk averse in their financial decision making when a negative stereotype about their group is salient.

\section{EXPERIMENT 2: CHOOSING A STOCK WITH DIFFERENT BETA LEVELS}

Experiment 2 expanded on the findings of Experiment 1 in two ways. First, it used a different way of activating a negative stereotype salient to participants. Experiment 1 specified a negative stereotype prominent in North America and its target group - that is, women for the math-gender stereotype. In Experiment 2, however, I did not specify a certain group membership or a type of stereotype to 
activate among participants, instead had them consider any negative stereotype associated with a meaningful group that they belong to. By doing so, I sought to suggest that the risk avoidance tendency could arise from any stereotype operating at the time of judgment without limiting to a certain type of stereotype in a society.

Second, Experiment 2 also used a different measure assessing consumers' risk preference in financial decision making. Specifically, this experiment varied beta scores of a stock and observed whether consumers prefer a stock with a lower (vs. higher) beta score when they self-generated a negative stereotype about their groups. Beta is a measure of a stock's volatility in relation to the market. Stocks with a beta greater than 1 indicate higher risk than the overall market yet provide a potential for higher returns. Thus, beta expresses the tradeoff between minimizing risk and maximizing return.

Putting it together, to find the predicted effects using this different manipulations and measures would strengthen my claims of the effect of feeling stereotyped on changing people's financial decision making.

\section{Method}

Participants and Design. A total of fifty-nine undergraduates participated in exchange for extra course credit. This study used a 2 (Stereotype Activation: Present vs. Absent) $\times 2$ (Stock: Low Beta vs. High Beta) design.

Procedures. Participants were given a set of questionnaires and told that short unrelated studies were group together into a session. Each study used a different font and style, aiming to appear as unrelated each other. The ostensible first study was to activate a negative stereotype among the participants in the experimental condition. Participants in the experimental condition (negative stereotype activation) were asked to list one of their group memberships that is particularly important and meaningful. Then they were asked to select one type of negative stereotype that other people may have toward their group (the group they mentioned above). They were asked to take some time to think about their personal experience or others' experience that they know of as related to this negative stereotype. Then they briefly wrote down in the box provided on the questionnaire. The participants in the 
control condition did not engage in this task.

Next, a study named "college students' understanding of financial terms" was presented, in order to have participants informed of the concept of beta as a popular indicator of risk in stock evaluation. Participants were told that I was developing financial education material for young consumers (college-aged individuals) to aid them in their investment decisions and I wanted to pre-examine how well financial terms are explained in our educational material. They were asked to evaluate a financial term followed, which was presented as an excerpt from our educational material, and to rate the clarity of the concept (appendix A). In the excerpt, the concept about beta was explained with examples that can provide participants a sense what higher versus lower beta scores than 1 means in terms of the trade of risk and potential payoff. After reading the excerpt, participants responded to two questions checking whether the participants understood the concept well.

Participants were then presented with "a stock pick of the week" by a financial consulting firm. In the high-risk condition, participants were given a stock with a beta score of 4.89 as a recommended one for the week, while people in the low-risk condition were given a stock with a beta score of .89 as a recommended one for the week. Participants then rated their intentions to invest in the stock using three seven-point items ( 1 = "dislike," "unappealing," and "unfavorable" to 7 = "like," "appealing," and "favorable"; $\alpha=.88$ ). A purchase intention index was created by averaging the $\mathrm{xx}$ items. Finally, participants were debriefed.

\section{Results}

Investment Intentions. I predicted that when participants considered a negative stereotype with their group, their intentions to invest in a recommended stock would be higher for the stock with a lower (vs. higher) beta score, compared to when participants did not consider a negative stereotype with their group. A 2 (risk: high vs. low) $\times 2$ (stereotype activation: presence vs. absence) ANOVA revealed the predicted two-way interaction effect of risk and stereotype activation $(F(1,55)=5.31, p<.05)$. No other effects were significant $(F \mathrm{~s}<1)$. Further analyses revealed that, consistent with the hypothesis, the participants in the stereotype activation condition preferred safer (less risky) investment ideas (i.e., portfolio 
of low-beta stocks) to riskier ideas $\left(M_{\text {Low Beta }}=4.24, S D=.98\right.$ vs. $M_{\text {High }}$ Beta $=3.48, S D=.96 ; F(1,55)=3.49, p<.07)$. On the other hand, there was no difference in preference among those in the control condition for whom no negative stereotype was activated $\left(M_{\text {Low Beta }}=\right.$ $3.52, S D=.92$ vs. $\left.M_{\text {High Beta }}=4.04, S D=1.21 ; F(1,55)=1.89, p>.18\right)$. Additionally, it was found that the participants in the stereotype activation condition showed higher intentions to invest in the lowbeta stock that those in the control condition $\left(M_{\text {Stereotype }}=3.48, S D\right.$ $=.96$ vs. $\left.M_{\text {Control }}=4.04, S D=1.21 ; F(1,55)=3.61, p<.07\right)$. These results replicate and extend experiment 1 's findings that when a negative ingroup stereotype is salient, consumers tend to avoid risk in financial decision making.

\section{Discussion}

In experiment 2, I used a different measure for risk avoidance tendency in financial decision making (i.e., a beta score for a stock) and a different method of activating a negative stereotype and found parallel effects as observed in experiment 1. Specifically, when people were first asked to think of a negative stereotype to their groups, people tended to prefer investing on a less risky and volatile stock compared to when people did not think about such negative ingroup stereotype.

\section{EXPERIMENT 3}

In Experiment 3, I employed a risk quotient developed by Hsee and Webber (1999), to measure people's risk preference in financial decision making.

\section{Method}

Participants and Design. Sixty-seven undergraduates, who participated in exchange for extra course credit, were randomly assigned to one of the two conditions - presence or absence of the activation of a negative group stereotype.

Procedures. The procedure was similar to that of Experiment 2. To be specific, participants in the experimental condition were first asked were asked to list their group memberships that are 
particularly important and meaningful. They were then asked to select one type of negative stereotype that other people may have toward their group (the group they mentioned above) and to provide an episode in detail. On the other hand, people in the control condition were only asked to think of their group memberships, but they were not asked to elaborate on a certain negative stereotype.

After that, participants were lead to do a study, titled "Study on Investment Styles." This study was modified from Hsee and Weber (1999) and measured their risk preference in investment by making people to gauge the risks and payoffs in investment choices. In the task, the participants were asked to select one of the two options for all seven scenarios. One option was to buy a particular "stock," which would provide them with a 50\% chance of earning $\$ 200$ and another $50 \%$ chance of earning $\$ 1,000$. The other option was to put the money in "a saving account," which return rate was fixed. Each scenario presented the two options - stock or savings - with the amount of sure earning only increased from $\$ 300$ (scenario 1) to $\$ 900$ (scenario 7; appendix B). I measured the point at which people switched from probabilistic to sure options and used that as a main dependent variable. After some other brief measures, participants were debriefed.

\section{Results and Discussion}

Risk Preference. Based on their choices in the seven scenarios, I assigned the risk preference index. I predicted that the activation of negative ingroup stereotype would risk avoidance tendency in investment decision. One factor (Stereotype activation: Present vs. Absent) ANOVA on risk preference index revealed the predicted effect $(F(1,65)=4.45, p<.05)$. In support of my hypothesis, I found that participants in the negative stereotype condition showed lower risk preference score compared to those in the control condition ( $M_{\text {negative }}$ stereotype $=2.97, S D=1.34$ vs. $M_{\text {control }}=3.61, S D=1.12$ ). This finding replicated the stereotype threat effect observed in experiments 1 and 2 in investment decision contexts.

\section{GENERAL DISCUSSION}

Most social groups are at times associated with negative traits, 
such as incompetence, avarice, or weaknesses. Society has tried to debunk negative stereotypes associated with social groups through education, public discourse, and the media. Undeniably, however, evidence from both academic research and everyday anecdotes suggests that negative stereotypes unduly influence people's judgments (Allport 1954; Eagly, Makhijani, and Klonsky 1992; Park and Rothbart 1982; Wheeler and Petty 2001). The current research adds another piece of evidence to the literature and show that members of stereotyped groups can stumble upon social or psychological obstacles while making financial and investmentrelated decisions. Specifically, I argued and found that under the influence of a negative stereotype, consumers became consistently withdrawn in pursuing potentially profitable investment, by becoming risk aversive. I demonstrated this effect in the diverse investment settings, such as portfolio creation using stocks versus bonds (Experiment 1), selection of stocks (Experiment 2), and a gamble with different pay-outs (Experiment 3).

The findings of this research is consistent with the effect of stereotype activation on goal adaptation, according to which being stereotyped makes people more focused on avoiding situations or outcomes that can reinforce the negative stereotype. For instance, Brodish and Devine (2009) found that under the influence of the math-gender stereotype (i.e., women's inferior math ability to men), women adopted the avoidance goal by focusing on avoiding poor performance on a math task rather than by focusing on doing better on the task. Similarly, by using the regulatory focus framework, Seibt and Forster (2004) showed that the activation of negative selfstereotypes induced a prevention focus, characterized by avoidance goals and aversive motivation. Also, Purdie-Vaughns and colleagues (2008) noted that, "if aspects of a setting convey devaluation of one's group identity, a person may choose not to enter the setting" (p. 616). That is, because the presence of outgroup members implies a higher probability of ingroup members being stereotyped (Wout et al. 2009), and because people held particularly negative feelings toward outgroup members when they felt that they would be stereotypically viewed by them (Vorauer, Main, and O'Connell 1998), people are more likely to avoid such situations with outgroup transaction partners when a negative ingroup stereotype is salient.

This research has important implications for the society, as well, in that financial decision making can have a substantial impact 
on well-being. For instance, female consumers, compared to male consumers, report feeling intimidated when it comes to discussing their portfolios with a financial planner because they believe they are less competent at investing (Koss-Feder 2006; Lee et al. 2011). Due to the negative stereotype about female consumers, women report turning away from finance and investment and toward frugality as a mode of wealth management (Oaff 2002). Since women (or any stigmatized people) tend to overly try to minimize risks involved in investment (thereby forego opportunities to grow assets and garner earnings), the current research suggests a possibility of serious negative consequences.

\section{REFERENCES}

Allport, G. W. (1954), The Nature of Prejudice, Reading, MA: Addison-Wesley. Brodish, A. B. and P. G. Devine (2009), "The Role of Performance-Avoidance Goals and Work in Mediating the Relationship between Stereotype Threat and Performance," Journal of Experimental Social Psychology, 45 (January), 180-85.

Davies, P. G., S. J. Spencer, and C. M. Steele (2005), "Clearing the Air: Identity Safety Moderates the Effects of Stereotype Threat on Women's Leadership Aspirations," Journal of Personality and Social Psychology, 88 (February), 276-87.

Eagly, A. H., M. G. Makhijani, and B. G. Klonsky (1992), "Gender and the Evaluation of Leaders: A Meta-Analysis," Psychological Bulletin, 111 (January), 3-22.

Hsee, C. K. and E. U. Weber (1999), "Cross-National Differences in Risk Preferences and Lay Predictions for the Differences," Journal of Behavioral Decision Making, 12 (2), 165-79.

Koss-Feder, L. (2006), "For Financial Advice, Women Turn to Female Pros," in Women's News.

Lee, K., H. Kim, and K. D. Vohs (2011), "Stereotype Threat in the Marketplace: Consumer Anxiety and Purchase Intentions," Journal of Consumer Research, 38 (August), 343-57.

Oaff, B. (2002), "Investment: Women Don't Get a Fair Deal," in The Independent. London.

Park, B. and M. Rothbart (1982), "Perception of out-Group Homogeneity and Levels of Social Categorization: Memory for the Subordinate Attributes of in-Group and out-Group Members," Journal of Personality and Social Psychology, 42 (June), 1051-68.

Purdie-Vaughns, V., C. M. Steele, P. G. Davies, R. Ditlmann, and J. 
R. Crosby (2008), "Social Identity Contingencies: How Diversity Cues Signal Threat or Safety for African Americans in Mainstream Institutions," Journal of Personality and Social Psychology, 94 (4), 61430.

Seibt, B. and J. Forster (2004), "Stereotype Threat and Performance: How Self-Stereotypes Influence Processing by Inducing Regulatory Foci," Journal of Personality and Social Psychology, 87 (1), 38-56.

Spencer, S. J., C. M. Steele, and D. M. Quinn (1999), "Stereotype Threat and Women's Math Performance," Journal of Experimental Social Psychology, 35 (January), 4-28.

Steele, C. M. (1997), "A Threat in the Air: How Stereotypes Shape Intellectual Identity and Performance," American Psychologist, 52, 613-29.

Steele, C. M. and J. Aronson (1995), "Stereotype Threat and the Intellectual Test Performance of African Americans," Journal of Personality and Social Psychology, 69 (November), 797-811.

Steele, C. M., J. Aronson, and S. J. Spencer (2007), "Stereotype Threat," in Encyclopedia of Social Psychology, ed. R. F. Baumeister and K. D. Vohs, Thousand Oaks, CA: Sage, 943 - 44

Vorauer, J. D., K. J. Main, and G. B. O’Connell (1998), "How Do Individuals Expect to Be Viewed by Members of Lower Status Groups? Content and Implications of Meta-Stereotypes," Journal of Personality and Social Psychology, 75 (October), 917-37

Wheeler, S. C. and R. E. Petty (2001), "The Effects of Stereotype Activation on Behavior: A Review of Possible Mechanisms," Psychological Bulletin, 127 (November), 797-826.

Wout, D. A., M. J. Shih, J. S. Jackson, and R. M. Sellers (2009), “Targets as Perceivers: How People Determine When They Will Be Negatively Stereotyped," Journal of Personality and Social Psychology, 96 (2), 34962. 


\title{
APPENDIX A STIMULUS USED IN EXPERIMENT 1
}

\begin{abstract}
We are developing financial education material for young consumers (college-aged individuals) for their investment decisions. Here, we want to pre-examine how well financial terms are explained in our educational material. You are asked to evaluate one financial term here, and to rate the clarity of the concept. The following is an excerpt from our educational material. Please read it carefully.
\end{abstract}

\subsubsection{Beta (Beta Risk, Beta Rate, Risk Index)}

As you can imagine, the concept of risk is hard to pin down and factor into stock analysis and valuation. Is there a rating--some sort of number, letter, or phrase--that will do the trick?

One of the most popular indicators of risk is a statistical measure called beta.

Beta is a measure of a stock's volatility in relation to the market. Put differently, the beta of a stock indicates the degree to which its price fluctuates in relation to the overall market. By definition, the market has a beta of 1.0, and individual stocks are ranked according to how much they deviate from the market. A stock that swings more than the market over time has a beta above 1.0. In other words, stocks with a beta greater than 1 indicate higher risk than the overall market. On the other hand, if a stock moves less than the market, that stock's beta is less than 1.0.

High-beta stocks are supposed to be riskier, but provide a potential for higher returns; lowbeta stocks pose less risk, but also lower returns. Thus, beta expresses the fundamental tradeoff between minimizing risk and maximizing return.

Say a company has a beta of 2 . This means it is two times as volatile as the overall market. Let's say we expect the market to provide a return of $10 \%$ on an investment. We would expect the company to return $20 \%$. On the other hand, if the market were to decline and provide a return of $-10 \%$, investors in that company could expect a return of $-20 \%$ (a loss of $20 \%$ ). If a stock had a beta of 0.5 , we would expect it to be half as volatile as the market. Similarly, a market return of $10 \%$ would mean a $5 \%$ gain for the company.

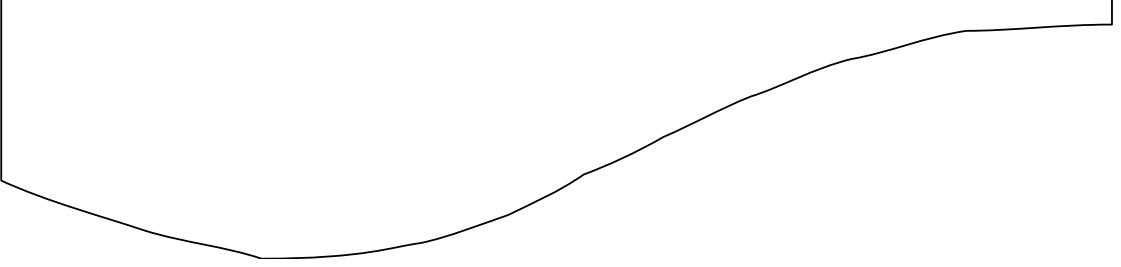




\section{APPENDIX B \\ INVESTMENT CHOICES SCENARIOS USED IN EXPERIMENT 3}

Read each scenario carefully and check option A or B for each scenario.

\begin{tabular}{|c|c|c|}
\hline Scenario & Option A [Stock] & Option B [Savings] \\
\hline \multirow[t]{2}{*}{1} & $\begin{array}{l}\text { A } 50 \% \text { chance of earning } \$ 200 \text { and } \\
\text { another } 50 \% \text { chance of earning } \$ 1,000\end{array}$ & A sure earning of $\$ 300$ \\
\hline & I would choose: Option A & Option B. (Please circle one.) \\
\hline \multirow[t]{2}{*}{2} & $\begin{array}{l}\text { A } 50 \% \text { chance of earning } \$ 200 \text { and } \\
\text { another } 50 \% \text { chance of earning } \$ 1,000\end{array}$ & A sure earning of $\$ 400$ \\
\hline & I would choose: Option $\mathbf{A}$ & Option B. (Please circle one.) \\
\hline \multirow[t]{2}{*}{3} & $\begin{array}{l}\text { A } 50 \% \text { chance of earning } \$ 200 \text { and } \\
\text { another } 50 \% \text { chance of earning } \$ 1,000\end{array}$ & A sure earning of $\$ 500$ \\
\hline & I would choose: Option A & Option B. (Please circle one.) \\
\hline \multirow[t]{2}{*}{4} & $\begin{array}{l}\text { A } 50 \% \text { chance of earning } \$ 200 \text { and } \\
\text { another } 50 \% \text { chance of earning } \$ 1,000\end{array}$ & A sure earning of $\$ 600$ \\
\hline & I would choose: Option $\mathbf{A}$ & Option B. (Please circle one.) \\
\hline \multirow[t]{2}{*}{5} & $\begin{array}{l}\text { A } 50 \% \text { chance of earning } \$ 200 \text { and } \\
\text { another } 50 \% \text { chance of earning } \$ 1,000\end{array}$ & A sure earning of $\$ 700$ \\
\hline & I would choose: Option $\mathbf{A}$ & Option B. (Please circle one.) \\
\hline \multirow[t]{2}{*}{6} & $\begin{array}{l}\text { A } 50 \% \text { chance of earning } \$ 200 \text { and } \\
\text { another } 50 \% \text { chance of earning } \$ 1,000\end{array}$ & A sure earning of $\$ 800$ \\
\hline & I would choose: Option A & Option B. (Please circle one.) \\
\hline \multirow[t]{2}{*}{7} & $\begin{array}{l}\text { A } 50 \% \text { chance of earning } \$ 200 \text { and } \\
\text { another } 50 \% \text { chance of earning } \$ 1,000\end{array}$ & A sure earning of $\$ 900$ \\
\hline & I would choose: Option $\mathbf{A}$ & Option B. (Please circle one.) \\
\hline
\end{tabular}

